\title{
Amostragem de terra para fins de fertilidade em função da ferramenta de amostragem
}

\author{
Ciro Antonio Rosolem ${ }^{1}$, Thiago de Souza Tozi ${ }^{2}$, Rodrigo Arroyo Garcia ${ }^{3}$
}

\section{RESUMO}

Embora existam indicações de que a pá de corte proporcione melhor qualidade de amostragem de terra para fins de análise de fertilidade, seu manuseio demanda muito tempo. No presente trabalho foram comparados os resultados da análise química de terra proveniente de 15 áreas distintas, cujas amostras foram obtidas com cinco tipos de trado e com pá de corte. Também foram comparados o tempo demandado para a realização do trabalho e o volume de terra coletado com as diferentes ferramentas, em dois solos de texturas distintas. O tempo médio de amostragem foi estimado, avaliando-se o tempo gasto por seis pessoas para tomar dez amostras. Para o estudo de qualidade de resultados foram amostradas 15 áreas, com solos, manejos e níveis de fertilidade distintos, de modo a se obter grande variação entre os valores das características avaliadas. As amostragens constaram da estratificação por profundidades e amostras de 0 a $20 \mathrm{~cm}$ de profundidade no teste de tempo. A amostragem com a pá de corte demora de 1,3 a 2,3 vezes mais do que com os trados. Para os valores de pH, matéria orgânica, acidez do solo, Al trocável e P disponível, os resultados foram equivalentes para todas as ferramentas empregadas. Entretanto, para as bases do solo (Ca, $\mathrm{Mg}$ e $\mathrm{K}$ ), as ferramentas empregadas resultaram, na maioria das vezes, em resultados diferentes dos obtidos pela pá de corte.

Palavras-chave: Análise de terra, fertilidade do solo, pá de corte, trado amostrador

\section{ABSTRACT}

\section{Quality of soil samples for soil fertility evaluation as affected by sampling tools}

Spade has been indicated in Brazil as the best tool for soil sampling to evaluate soil fertility, but its use is time consuming. In the present study the results of five different tools including augers, tubes and a power driven screw were compared with trowel samples as to the time consumed to sample the soil and results quality. The average time to take 10 samples was evaluated by 6 different operators. To evaluate the sample results quality, 15 areas differing in soil type, management and fertility level were sampled. The samples were taken according to soil depth or taken from 0 to $20 \mathrm{~cm}$ as a standard sample in Brazil. Sampling with a trowel took 1.3 to 2.3 more time than soil sampling with the other tools. For soil organic matter, acidity, exchangeable $\mathrm{Al}$ and available $\mathrm{P}$ all the tools can be used without difference in results quality. However, for the soil bases $\mathrm{K}$, Ca and Mg results obtained with different tools were not comparable.

Key words: Soil analysis, soil auger, soil fertility

\footnotetext{
Recebido para publicação em fevereiro de 2009 e aprovado em março de 2010

${ }^{1}$ Engenheiro-Agrônomo, Doutor. Departamento de Produção Vegetal, Faculdade de Ciências Agronômicas de Botucatu, Universidade Estadual Paulista "Julio de Mesquita Filho”. Rua José Barbosa de Barros, 1780, 18603970, Botucatu, São Paulo, Brasil. rosolem@fca.unesp.br.

${ }^{2}$ Engenheiro-Agrônomo. Mestre. Departamento de Produção Vegetal. FCA-UNESP/Botucatu. Rua José Barbosa de Barros, 1780, 18603970, Botucatu, São Paulo, Brasil.

${ }^{3}$ Engenheiro-Agrônomo. Doutorando do Departamento de Produção Vegetal. FCA-UNESP/Botucatu. Rua José Barbosa de Barros, 1780, 18603970, Botucatu, São Paulo, Brasil. ragarcia@fca.unesp.br.
} 


\section{INTRODUÇÃO}

A evolução dos procedimentos analíticos e dos equipamentos utilizados para retirada de amostras de terra para fins de análise da fertilidade tem sido rápida, mas poucos são os trabalhos sobre os melhores métodos e ferramentas utilizados para a coleta de amostras no campo (Bacchi et al., 1995). Schlindwein \& Anghinoni (2000) mostraram que a coleta de pequenas amostras com os trados de rosca ou calador, no sistema de semeadura direta, é problemática, pois a variação dos resultados é muito grande. $\mathrm{O}$ coeficiente de variação (CV) foi da ordem de $67 \%$, na amostragem com trado de rosca para fósforo disponível, com adubação em sulcos, enquanto, com a pá de corte, o CV foi de 33\% (Schlindwein \& Anghinoni, 1998). Para se obter um intervalo de variação aceitável, haveria necessidade de se coletar 183 subamostras com trado de rosca e 44 subamostras com pá de corte. Em lavoura com adubação a lanço, o CV foi menor na amostragem com trado de rosca (47\%), resultando na necessidade de coletar 92 subamostras, enquanto para a pá de corte, o número de subamostras permaneceu em 44. Assim, o emprego do trado de rosca resultou na necessidade de se coletar elevado número de subamostras para os limites de precisão adotados. O mesmo estudo mostrou, ainda, que os valores para fósforo disponível foram $30 \%$ menores na lavoura com adubação no sulco e amostragem com trado de rosca, em relação à amostragem com pá de corte. Essa diferença foi atribuída à perda de solo da parte superior da amostra, mais rica nesse nutriente, com o uso do trado de rosca.

No experimento de Oliveira et al. (2007), de modo geral, a variabilidade dos índices de fertilidade do solo foi maior para o trado de caneca do que para a pá de corte, independentemente do tipo de preparo do solo. Em contrapartida, a fertilidade média de uma gleba de solo sob plantio direto ou convencional, após a colheita e antes do preparo do solo subsequente, pode ser avaliada com o trado de caneca, em substituição à pá de corte, desde que, na preparação da amostra composta de solo, $17 \%$ das amostras simples sejam coletadas no sulco de plantio, $33 \%$ a $10 \mathrm{~cm}$ do sulco e $50 \%$ no ponto médio entre os sulcos.

Raij et al. (1996) admitiram que a coleta de amostras pode ser feita com enxadão, pá de corte ou, preferencialmente, com trado. Os trados tipo holandês, tubo ou de caneca, tornam a operação mais fácil e rápida. Além disso, permitem a retirada das amostras na profundidade correta e das mesmas quantidades de terra de todos os pontos amostrados. Silva \& Machado (1997), comparando o enxadão, a cavadeira, o trado holandês e a sonda, constataram que o trado e a sonda proporcionaram menores valores para os teores de Ca na cama- da 0 - $20 \mathrm{~cm}$. Na camada de 20 - $40 \mathrm{~cm}$ não foram observadas diferenças significativas para $\mathrm{pH}, \mathrm{Ca}, \mathrm{Mg}$ e $\mathrm{K}$, mas o trado holandês e a sonda levaram à obtenção de maiores valores para $\mathrm{H}+\mathrm{Al}$, P e matéria orgânica. Assim, a contaminação de amostras coletadas na profundidade de 20 - $40 \mathrm{~cm}$, por terra da camada superior, é maior quando se utiliza o trado holandês e a sonda, levando a resultados superestimados.

Embora existam indicações de que a pá de corte proporcione melhor amostragem (Schlindwein \& Anghinoni, 2002; Oliveira et al., 2007; Alvarez \& Guarçoni, 2003), seu manuseio demanda muito tempo, o que pode ser limitante quando da amostragem de grandes áreas, principalmente com a implantação de sistemas com maior precisão no manejo e taxa de aplicação de acordo com as necessidades de cada área. Dessa forma, existe uma tendência do mercado em oferecer ferramentas que melhorem o rendimento do trabalho, mas a qualidade de amostragem tem sido pouco considerada. A literatura sobre o assunto é escassa, não havendo estudos sistemáticos que permitam concluir definitivamente sobre o melhor tipo de ferramenta a ser empregada. Portanto, no presente trabalho, pretendeu-se comparar cinco tipos de amostradores com a pá de corte, quanto aos atributos químicos do solo, de amostras provenientes de 15 áreas distintas. O tempo demandado para a realização do trabalho e o volume de terra coletado também foram comparados em função da ferramenta de amostragem, em dois solos com diferentes texturas.

\section{MATERIAL E MÉTODOS}

O presente estudo constou de três experimentos, realizados nas Fazendas Experimentais da Faculdade de Ciências Agronômicas/UNESP, nos municípios de Botucatu e São Manuel, SP.

\section{Tempo demandado na amostragem de solo em função da ferramenta}

Um ensaio de tempo para amostragem foi executado em solo de textura argilosa, classificado como Nitossolo eutrófico (EMBRAPA, 1999), e o outro foi realizado em solo de textura média, classificado como Latossolo Vermelho distroférrico (EMBRAPA, 1999). As áreas estavam em pousio desde o manejo da cultura de inverno (aveia preta). Alguns dias antes da execução do trabalho, a vegetação espontânea foi roçada e seis blocos em cada tipo de solo foram demarcados. A seguir, dez parcelas de 3,0 m X 3,0 m foram delimitadas por bloco.

Seis pessoas se revezaram em uma seqüência de coletas, cada uma usando todas as ferramentas. Determinouse o tempo que cada operador gastou para fazer a coleta das dez parcelas, incluindo a retirada do solo do trado e o 
seu acondicionamento. As amostras foram retiradas aleatoriamente dentro das parcelas, à profundidade de 0 a 20 $\mathrm{cm}$. Para o tempo de amostragem, foram feitas coletas apenas na profundidade de $0-20 \mathrm{~cm}$. Os procedimentos, os operadores e as ferramentas de coleta foram os mesmos para os dois solos.

As ferramentas utilizadas foram: 1. Trado de rosca: haste de aço inox maciça, com $20 \mathrm{~mm}$ de diâmetro e $400 \mathrm{~mm}$ de comprimento, acoplada a uma rosca de aço com $180 \mathrm{~mm}$ de comprimento por 17,5 mm de diâmetro, acionada por furadeira elétrica a bateria; 2 . Trado holandês: tubo de aço, com 700 mm de comprimento e 25 mm de diâmetro, caneca coletora com aberturas laterais de $180 \mathrm{~mm}$ de comprimento por $80 \mathrm{~mm}$ de largura, com rosca de $20 \mathrm{~mm}$ de comprimento por $10 \mathrm{~mm}$ de largura na ponteira; 3. Trado sonda fechado: tubo de aço inox, com $700 \mathrm{~mm}$ de comprimento, 23,5 mm de diâmetro externo e 19,5 mm de diâmetro interno, com ponteira cônica (com 17,5 mm de diâmetro interno na ponta do cone) acoplada em uma das extremidades. 4 . Trado sonda aberto: tubo de aço inox temperado (TP-420), com $700 \mathrm{~mm}$ de comprimento, 31,5 mm de diâmetro externo e 25,5 mm de diâmetro interno, com abertura oblonga de 150 x 15 mm em uma das extremidade; 5. Pá de corte: pá de corte, com 360 mm de comprimento por 200 mm de largura, acoplada em um cabo de madeira com 1,50 m de comprimento (as amostras constituíram-se nos $10 \mathrm{~cm}$ do meio da pá); 6. Trado de caneca: haste de aço maciça, com $700 \mathrm{~mm}$ de comprimento por $25 \mathrm{~mm}$ de diâmetro, acoplada a uma caneca coletora cilíndrica, de aço, com $100 \mathrm{~mm}$ de comprimento por $45 \mathrm{~mm}$ de diâmetro interno.

No dia da amostragem, em cada solo foram abertas quatro trincheiras, distribuídas aleatoriamente entre os blocos experimentais, para coleta de amostras ao longo do perfil, visando à determinação da granulometria e do teor de água. Amostras indeformadas dos dois tipos de solo foram coletadas para determinação da capacidade de retenção de água a -0,01 MPa (capacidade de campo). Além das trincheiras, foram feitas seis determinações para caracterizar a resistência mecânica do solo à penetração, em pontos aleatórios entre os blocos, com um penetrógrafo com haste de $60 \mathrm{~cm}$ de comprimento munida de ponteira cônica. As análises granulométricas e do teor e retenção de água no solo, na capacidade de campo (Tabela 1), seguiram os procedimentos da EMBRAPA(1997). Na Figura 1, estão apresentados os teores de água ao longo do perfil dos dois tipos de solo e os respectivos valores da resistência mecânica à penetração.

O delineamento experimental foi em blocos ao acaso com seis repetições. O tempo de amostragem foi anotado em minutos e as médias dos seis operadores (seis repetições), para cada ferramenta de coleta, foram comparadas pelo teste Tukey a 5\% de probabilidade, de acordo com Mischan \& Pinho (1996).

\section{Quantidade de terra coletada por diferentes ferramentas}

Em cada um dos dois tipos de solo foram demarcados quatro blocos com dez parcelas de 1,0 x 1,0 m por bloco. Nestas parcelas foram retiradas, por um mesmo operador, amostras com os cinco trados e com a pá de corte, nas profundidades de 0-5, 5-10, 10-20, 20-40 e 0-20 cm. Foram utilizadas nas ferramentas fitas adesivas como referência da exata profundidade de terra amostrada. As amostras coletadas foram secas em estufa de aeração forçada a $40^{\circ} \mathrm{C}$, por 72 horas. Em seguida, o solo foi destorroado, passado em peneira com malha de $2 \mathrm{~mm}$ e a massa foi determinada. Foi feita análise de variância, considerando-se um delineamento em blocos ao acaso, com quatro repetições e seis tratamentos (ferramentas). As médias de cada ferramenta, para cada profundidade, foram comparadas pelo teste Tukey a 5\% de probabilidade (Mischan \& Pinho, 1996).

\section{Qualidade de Amostragem de solo}

Foram escolhidas 15 áreas, com históricos diferentes de manejo, de modo a se obterem amostras com teores variados de nutrientes. As áreas escolhidas para coleta de terra para os testes tinham as seguintes características:

1. Pousio, Latossolo Vermelho distroférrico: Fazenda Experimental Lageado (FCA/Unesp), em Botucatu-SP, há mais de 20 anos mantida com Brachiaria decumbens Stapf Prain em pousio.

2. Produção de soja em semeadura direta, Latossolo Vermelho distroférrico: Fazenda Experimental Lageado, ocupada há quatro anos com a sucessão de culturas soja - aveia preta - milheto, em semeadura direta.

3. Mata nativa, Latossolo Vermelho distroférrico: Fazenda Experimental Lageado, ocupada com vegetação nativa. A vegetação é classificada como Floresta Tropical Subperenifólia.

4. Produção de culturas graníferas em semeadura direta, Nitossolo Vermelho eutrófico de textura argilosa: há 16 anos ocupada com milho, soja, feijão, trigo e triticale, em semeadura direta.

5. Produção de culturas graníferas com preparo convencional, Nitossolo Vermelho eutrófico: Fazenda Experimental Lageado, há 16 anos ocupada com milho, soja, feijão, trigo e triticale, com preparo convencional do solo (aração + gradagem).

6. Soja em semeadura direta, Nitossolo Vermelho distrófico: Fazenda Experimental Lageado, há quatro anos com a sucessão de culturas soja - milheto em semeadura direta.

7. Reflorestamento, Latossolo Vermelho distroférrico: Fazenda Experimental Lageado, reflorestamento de eucalipto implantado há mais de 30 anos. 
Tabela 1. Resultados da análise granulométrica e da capacidade de retenção de água do solo na capacidade de campo, em amostras coletadas de 0 a $20 \mathrm{~cm}$ de profundidade, dos dois tipos de solo utilizados nos experimentos.

\begin{tabular}{|c|c|c|c|}
\hline \multirow{2}{*}{ Tipo de solo } & \multicolumn{3}{|c|}{ Granulometria } \\
\hline & Areia & Silte & Argila \\
\hline & & $\mathrm{g} \mathrm{kg}^{-1}$ & \\
\hline Argiloso & 110 & 210 & 680 \\
\hline \multirow{2}{*}{ Textura média } & 670 & 20 & 310 \\
\hline & \multicolumn{3}{|c|}{ — Retenção de água na capacidade de campo ( $\mathrm{g} \mathrm{kg}^{-1}$ de solo) } \\
\hline Argiloso & & 298 & \\
\hline Textura média & & 154 & \\
\hline
\end{tabular}
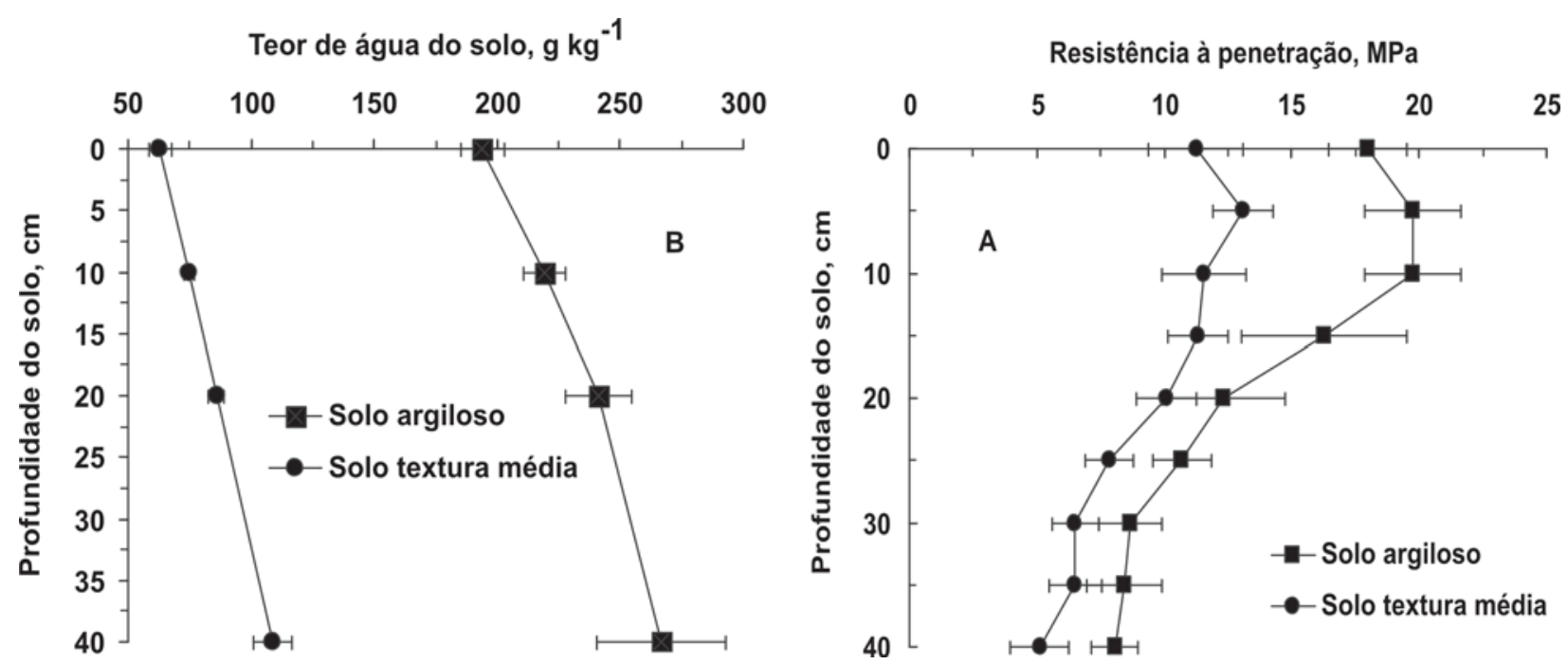

Figura 1: Condições de resistência à penetração (A) e umidade do solo (B) por ocasião do teste de tempo demandado para amostragem, em dois solos de Botucatu, SP.

8. Hortaliças, Latossolo Vermelho-Amarelo distroférrico: Área da Fazenda Experimental São Manuel (FCA/ Unesp), em São Manuel-SP; hortaliças há mais de 20 anos.

9. Pasto de solo arenoso, Neossolo: Área da Fazenda Experimental São Manuel; pasto de Brachiaria decumbens há mais de 20 anos.

10. Pasto degradado, Latossolo Vermelho-Amarelo distroférrico, de textura arenosa: Área da Fazenda Experimental São Manuel; pasto de Brachiaria decumbens há mais de 20 anos.

11. Pasto adubado, Argissolo Vermelho- Amarelo distroférrico, de textura média: Área da Fazenda Experimental Edgardia (FCA/Unesp), em Botucatu-SP; pasto de Brachiaria decumbens implantado há mais de 20 anos, manejado periodicamente com adubação.

12. Cerrado nativo, Latossolo Vermelho-Amarelo distroférrico, de textura média: Área da Fazenda Experimental São Manuel; mantida como remanescente do cerrado nativo.

13. Milho com preparo convencional do solo, Nitossolo Vermelho eutrófico de textura argilosa: Área da Fa- zenda Experimental Lageado; produção de milho, com preparo convencional do solo.

14. Café, Nitossolo Vermelho distrófico: Área da Fazenda Experimental Lageado, há mais de 30 anos com café.

15. Pasto, Nitossolo Vermelho distrófico: Área da Fazenda Experimental Lageado; pasto para a criação de bubalinos.

Em cada uma das áreas foi escolhido um ponto, aleatoriamente, onde foi marcado um quadrado de $0,16 \mathrm{~m}^{2}$, de onde foram tiradas as amostras com as seis ferramentas. As amostragens foram feitas às profundidades de 0-5, 510, 10-20, 20-40 e 0-20 cm.

Em áreas com culturas anuais, com distâncias entre linhas de semeadura variando de 0,40 m (soja) até 0,90 m (milho), o quadrado de 0,40 x 0,40 m ficou entre sulcos de semeadura. Em áreas com culturas perenes (café e eucalipto), a demarcação foi feita no meio das entrelinhas. Em área de hortaliças, fez-se a coleta de solo com o gabarito fixado em cima do canteiro, três meses após o término do ciclo da alface. Em áreas de pastagem, em pousio e em mata e cerrado nativos, o gabarito foi fixado aleatoriamente. 
Após a retirada das amostras com os trados, trincheiras de $0,20 \times 0,20 \times 0,40 \mathrm{~m}$ de profundidade foram abertas dentro de cada área de coleta, para a retirada das amostras com a pá de corte. As quantidades de solo retiradas com o trado rosca e tubular fechado são bastante reduzidas, por isso foi preciso fazer mais de uma amostragem (subamostra) dentro de cada ponto de coleta (seis subamostras para o trado rosca, e quatro para o tubular fechado).

As amostras de solo foram secadas em estufa de aeração forçada por 72 horas, a $\quad 40^{\circ} \mathrm{C}$. Em seguida, a terra seca foi destorroada e passada em peneira com malha de 2 mm. As análises químicas foram realizadas de acordo com Raij et al. (2001).

No estudo estatístico dos atributos químicos do solo, aplicou-se o modelo matemático de correlação de concordância (Zar, 1996). Foram feitas comparações entre os cinco trados com a pá de corte, para cinco profundidades, considerando-se como populações as coletas feitas em 15 áreas com características distintas. Objetivou-se, com a correlação de concordância, identificar qual o trado que mais se assemelha à pá de corte em termos de qualidade de amostragem, considerando-se uma ampla gama de variação nos teores.

\section{RESULTADOS E DISCUSSÃO}

\section{Tempo demandado para amostragem em função da ferramenta}

Para o solo de textura média, o menor tempo foi demandado pelo trado de rosca e o maior pela pá de corte (Figura 2A), sendo que os coeficientes de variação foram semelhantes para os dois solos, em torno de $20 \%$. No solo argiloso, não houve diferença de desempenho entre as amostragens feitas com trado holandês, de rosca, tubular aberto, tubular fechado e de caneca, mas a pá de corte demandou tempo de coleta significativamente maior.

No solo com textura média, de forma geral, todos os trados testados proporcionaram maior rapidez de coleta, quando comparados com o rendimento no solo argiloso (Figura 2A). A textura do solo pode fazer com que o tempo de amostragem seja prolongado por dois fatores, sendo o primeiro a plasticidade do solo, no que diz respeito à adesão da amostra à ferramenta de coleta e, o segundo, a resistência mecânica do solo à penetração. É possível dividir a velocidade de amostragem, em solos de textura média, em três grupos: a) o de maior rendimento, com o trado de rosca; b) o de rendimento intermediário, com os trados holandês, tubular fechado, de caneca e tubular aberto; c) de desempenho inferior, com pá de corte. Com a pá, demorou-se de 1,3 a 2,3 vezes mais para a coleta de uma amostra de terra (Figura 2A).
De acordo com Schlindwein \& Anghinoni (1998), seriam necessárias de 2,5 a 4 vezes mais amostras pequenas para cada amostra retirada com pá de corte, de modo que a vantagem verificada no presente trabalho seria irrelevante. Entretanto, normalmente é recomendado que se tomem diversas amostras simples para representar uma determinada área. Assim, como também com a pá de corte seriam necessárias várias amostragens, permanece a vantagem de menor tempo, verificada para as outras ferramentas no presente trabalho.

\section{Massa de terra coletada em função do tipo de ferramenta}

As diferentes ferramentas levaram à obtenção de diferentes massas de terra coletada, tanto na amostragem estratificada por profundidade (Figura 2B), como em amostras tomadas de 0 a $20 \mathrm{~cm}$ (Figura 2C). De modo geral, a pá de corte coletou maiores quantidades, seguida pelos trados de caneca e holandês, tendo os trados tubular aberto, tubular fechado e de rosca, coletado as menores quantidades.

Um ponto importante na amostragem de solo, para fins de análise química para recomendação de calagem e fertilizantes, é a quantidade de amostra coletada. Portanto, dependendo das determinações químicas planejadas, alguns tipos de trado podem ser inadequados, ou ainda, pode ser necessário aumentar o número de subamostras para formar uma amostra composta. De modo geral, nas amostras estratificadas, com o trado holandês, o de caneca e a pá foram obtidas amostras com mais de $100 \mathrm{~g}$ de terra, uma quantidade suficiente (Figura 2B), considerando-se uma amostra simples, para a maioria das aplicações em fertilidade do solo. Mesmo os outros trados, que retiraram amostras com massa ao redor de 50 g, não seriam limitantes, pois são necessárias várias amostras simples (Raij et al., 1996) para compor uma amostra composta. Assim, o pequeno volume pode até ser uma vantagem, pois diminui o volume de amostra a ser descartado, que pode se constituir em uma fonte de erro na amostragem. Os problemas levantados por Schlindwein \& Anghinoni (2000), a respeito de diferenças entre áreas com adubação no sulco e semeadura direta, e Schlindwein \& Anghinoni (1998), a respeito do número de amostras, poderiam ser contornados, no caso dos trados tubulares e de rosca, por meio da obtenção de número adequado de subamostras para compor a amostra composta.

\section{Qualidade da amostragem}

Para o pH, na camada de $0-5 \mathrm{~cm}$ de profundidade, com exceção do tipo caneca, os trados apresentaram desempenho semelhante ao da pá de corte (Tabela 2). Na coleta feita de 0-20 cm, o melhor coeficiente de concordância foi do trado sonda aberto. De maneira geral, com exceção da 
camada de 10-20 cm, o trado de caneca apresentou resultados de coeficiente de concordância inferiores aos demais, com valores abaixo de 0,91. Contudo, pode-se considerar que os valores de $\mathrm{pH}$ obtidos ao longo do perfil do solo apresentaram coeficientes de concordância altos e acima de 0,92, em função do tipo de ferramenta utilizada para amostragem, com exceção do trado de caneca e da profundidade de $10-20 \mathrm{~cm}$. No trabalho de Schlindwein \& Anghinoni (2002), independentemente do modo de aplicação de fertilizantes (lanço ou linha), os valores de $\mathrm{pH}$, do solo coletado com a pá de corte e com o trado de rosca, foram semelhantes.

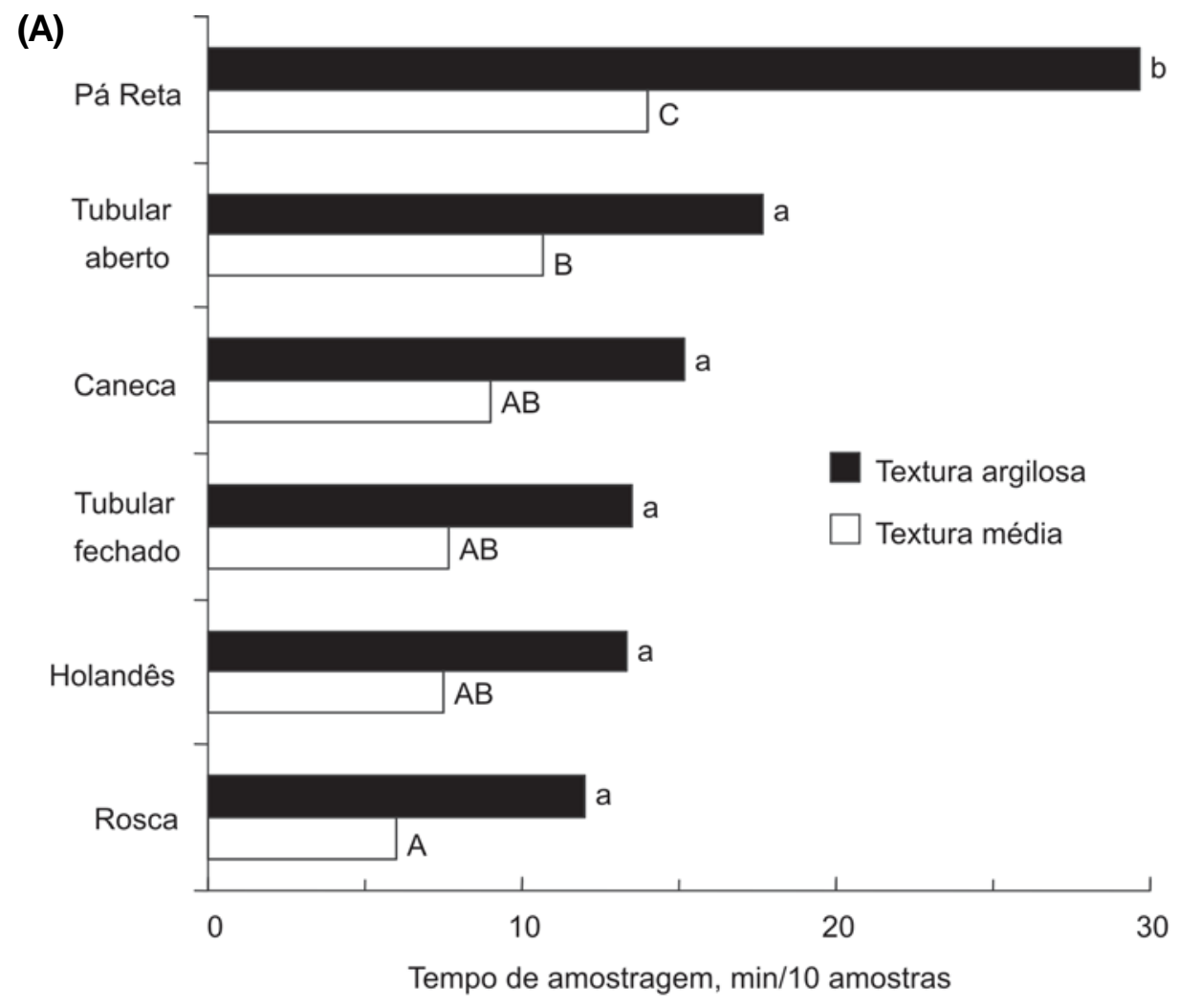

(B)

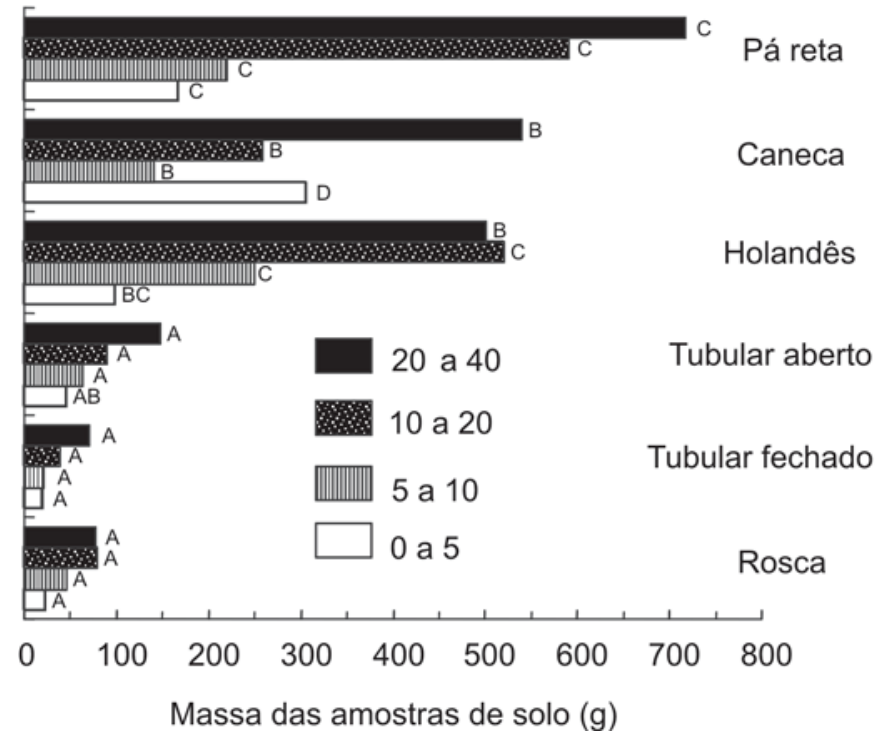

(C)

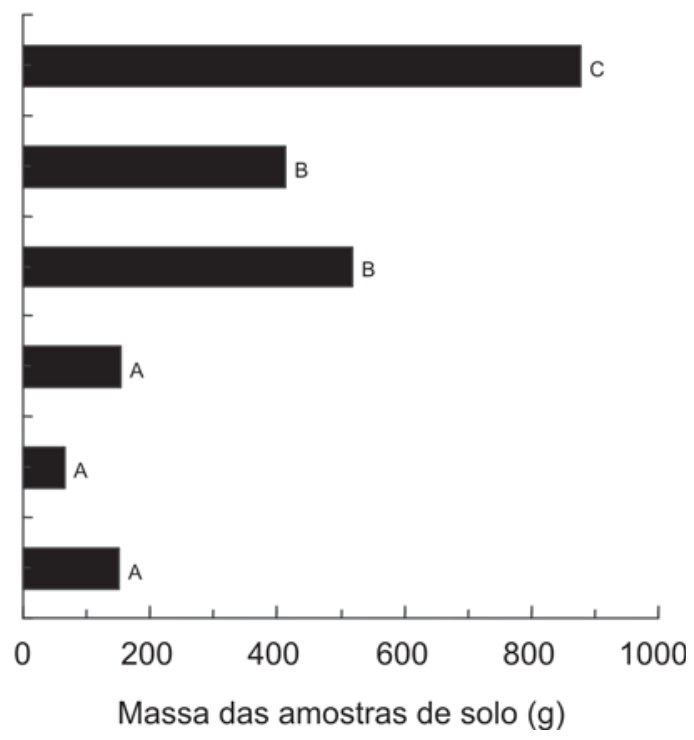

Figura 2: (A) Tempo gasto para tirar 10 amostras da camada 0 - $20 \mathrm{~cm}$ em dois tipos de solo. Média de 6 repetições. Letras diferentes (minúsculas para o solo argiloso e maiúsculas para o solo de textura media) indicam diferenças significativas pelo teste de Tukey (P $<0.05$ ). (B) Volume de terra coletado com cada ferramenta por ponto de amostragem no solo de textura média; (C) amostragem de 0 a $20 \mathrm{~cm}$.

Rev. Ceres, Viçosa, v. 57, n.3, p. 405-414, mai/jun, 2010 
Com relação à matéria orgânica, na profundidade de 0 $5 \mathrm{~cm}$, os coeficientes de concordância mais próximos de 1,0 foram obtidos com o trado sonda aberto e com o trado de caneca (Tabela 2). Para todas as outras profundidades avaliadas, independentemente do trado utilizado, os coeficientes de concordância foram inferiores a 0,91, ou seja, em princípio, todos os trados diferiram consideravelmente da pá de corte em camadas subsuperficiais. Para as amostragens feitas a $0-20 \mathrm{~cm}$ de profundidade, todos os coeficientes de concordância foram iguais ou inferiores a 0,81 . Estes resultados mostram que, quando não se estratifica a coleta de solo ao longo do perfil, a amostragem feita com a pá de corte, para caracterizar a matéria orgânica, diverge consideravelmente dos trados.

Para o fósforo disponível, todos os trados apresentaram altos coeficientes de concordância com a pá (Tabela 2), em todas as camadas amostradas. Também na camada de 0 $20 \mathrm{~cm}$ (sem estratificação do perfil), os resultados foram bastante semelhantes em termos de coeficiente de concordância. Schlindwein \& Anghinoni (1998) verificaram que, com trado de rosca, os resultados para fósforo foram menores que aqueles obtidos com a pá e os autores atribuíram esta diferença à perda de solo da camada mais superficial na amostragem com o trado rosca, o que não aconteceu no presente trabalho. Porém, o trabalho supracitado foi conduzido em sistema plantio direto e, no experimento em questão, as amostras de terra foram provenientes de 15 áreas com grande variabilidade de histórico e manejo.

Para a acidez potencial, na coleta realizada de $0-20 \mathrm{~cm}$ de profundidade, os coeficientes de concordância foram inferiores a 0,50, mostrando que os cinco trados avaliados são diferentes da pá de corte quando a amostragem do solo não é estratificada (Tabela 2). Com a estratificação do perfil do solo, os coeficientes de correlação entre os trados e a pá de corte foram relativamente altos, com exceção do trado de rosca, na camada de $0-5 \mathrm{~cm}$. Para o alumínio trocável, todos os trados apresentaram coeficiente de concordância superior a 0,90, em comparação com a pá de corte (Tabela 2). Estes resultados mostram que nenhum trado compromete a quantificação do $\mathrm{Al}^{3+}$ ao longo do perfil do solo, quando se considera ideal a amostragem feita com a pá de corte. Mesmo na amostragem sem estratificação $(0-20 \mathrm{~cm})$, as concordâncias entre os trados e a pá de corte foram próximas de 1,0.

No caso do cálcio trocável, na camada de 0-5 cm de profundidade, os maiores coeficientes de concordância foram 0,82 e 0,89, para os trados sonda fechado e aberto, respectivamente (Tabela 2). Na profundidade de 5-10 cm, a melhor concordância também foi para o trado sonda aberto. Nas profundidades de 10-20 cm e $20-40 \mathrm{~cm}$, assim como na amostragem não estratificada $(0-20 \mathrm{~cm})$, os maiores coeficientes de concordância para caracterizar o $\mathrm{Ca}^{2+}$ do solo foram para o trado de caneca.
Da mesma forma que ocorreu no caso do cálcio, os maiores coeficientes de concordância para os teores de magnésio trocável (Tabela 2), foram dos trados tubular aberto e fechado, na camada de $0-5 \mathrm{~cm}$ de profundidade. Na camada de 0-20 cm (amostragem não estratificada), os valores de concordância não atingiram 0,90. Em sub-superfície (10-20 cm e 20-40 cm), os valores de concordância foram maiores para o trado holandês e o de caneca. No trabalho de Alvarez \& Guarçoni (2003), em que foi avaliada a variabilidade horizontal dos atributos químicos do solo, em amostras coletadas com trado de caneca e pá de corte, observou-se alta variabilidade para os teores de $\mathrm{Mg}$, no entanto, os valores obtidos pelas diferentes ferramentas foram iguais.

No caso do potássio (Tabela 2), os valores de concordância entre os trados e a pá de corte foram relativamente menores, quando comparados aos obtidos para o cálcio e para o magnésio. Os menores coeficientes de concordância foram verificados no caso do trado de rosca, com exceção da camada de 5-10 cm. Em nenhuma situação estudada, os coeficientes de concordância entre trados e a pá de corte atingiram valores iguais ou acima de 0,90 , para todas as camadas do solo avaliadas.

Com relação à qualidade da amostragem, os resultados mostraram que as ferramentas são equivalentes para muitas aplicações. Praticamente, todos os trados testados no presente trabalho têm potencial para substituir a pá de corte, no que se refere à caracterização da acidez potencial do solo em camadas estratificadas, com exceção da amostragem tradicional $(0-20 \mathrm{~cm})$, o que é de difícil explicação. Isso pode ser um problema nas situações em que se usa a acidez potencial como parâmetro para o cálculo da calagem. Entretanto, para as bases trocáveis do solo, o uso de amostradores alternativos à pá de corte pode comprometer a qualidade da amostragem.

Na Tabela 3 e Figura 3, estão apresentadas as médias, assim como a dispersão dos teores obtidos com as diversas ferramentas, ficando evidente que é muito difícil estabelecer qualquer tipo de relação entre elas, pois a dispersão de valores é grande. Entretanto, comparando-se a dispersão relativa (\%), nota-se que, para o Ca e Mg não há relação significativa entre o valor obtido para o teor no solo com a magnitude do desvio padrão (Tabela 3). Já para o K, além de significativo no nível de $5 \%$, o valor de r é negativo, ou seja, quanto maior o teor, menor a variabilidade obtida. Em trabalho desenvolvido por Oliveira et al. (2007), a variabilidade dos índices de fertilidade do solo foi, de modo geral, maior para o trado de caneca do que para a pá de corte, independentemente do tipo de preparo do solo. Para os dois instrumentos de coleta das amostras, os atributos químicos do solo apresentaram a seguinte ordem decrescente de variabilidade: $\mathrm{Mg}^{2+}>\mathrm{K}^{+}$ $>\mathrm{Ca}^{2+}>\mathrm{MO}>\mathrm{pH}$. 
Tabela 2. Coeficientes de concordância calculados para os resultados de análise de terra para fins de fertilidade, para amostras coletadas ao longo do perfil do solo de 15 áreas distintas, comparando a qualidade de amostragem da pá de corte a cinco tipos de trado.

\begin{tabular}{|c|c|c|c|c|c|}
\hline $\begin{array}{l}\text { Profundidade do } \\
\text { solo }(\mathrm{cm})\end{array}$ & $\begin{array}{c}\text { Pá de corte } x \\
\text { Rosca }\end{array}$ & $\begin{array}{c}\text { Pá de corte } x \\
\text { Sonda fechada }\end{array}$ & $\begin{array}{l}\text { Pá de corte } x \\
\text { Sonda aberta }\end{array}$ & $\begin{array}{c}\text { Pá de corte } x \\
\text { Holandês }\end{array}$ & $\begin{array}{c}\text { Pá de corte } x \\
\text { Caneca }\end{array}$ \\
\hline & & & $-\mathrm{pH} \longrightarrow$ & 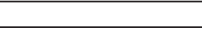 & 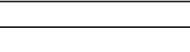 \\
\hline $0-5$ & 0,97 & 0,97 & 0,97 & 0,98 & 0,91 \\
\hline $5-10$ & 0,93 & 0,95 & 0,96 & 0,97 & 0,83 \\
\hline $10-20$ & 0,90 & 0,85 & 0,87 & 0,85 & 0,95 \\
\hline $20-40$ & 0,98 & 0,97 & 0,96 & 0,94 & 0,83 \\
\hline $0-20$ & 0,94 & 0,95 & 0,97 & 0,92 & 0,87 \\
\hline $0-5$ & 0,85 & 0,83 & 0,97 & 0,92 & 0,97 \\
\hline $5-10$ & 0,75 & 0,71 & 0,74 & 0,83 & 0,61 \\
\hline $10-20$ & 0,76 & 0,81 & 0,83 & 0,82 & 0,91 \\
\hline $20-40$ & 0,84 & 0,85 & 0,82 & 0,79 & 0,86 \\
\hline \multirow[t]{2}{*}{$0-20$} & 0,81 & 0,81 & 0,77 & 0,59 & 0,72 \\
\hline & & & Fósforo & & \\
\hline $0-5$ & 0,91 & 0,92 & 0,96 & 0,93 & 0,89 \\
\hline 5-10 & 0,97 & 0,95 & 0,97 & 0,93 & 0,91 \\
\hline $10-20$ & 0,99 & 0,99 & 0,99 & 0,99 & 0,98 \\
\hline $20-40$ & 0,93 & 0,97 & 0,97 & 0,99 & 0,98 \\
\hline $0-20$ & 0,98 & 0,99 & 0,96 & 0,99 & 0,98 \\
\hline $0-5$ & 0,73 & 0,98 & 0,98 & 0,98 & 0,95 \\
\hline $5-10$ & 0,96 & 0,95 & 0,96 & 0,96 & 0,93 \\
\hline $10-20$ & 0,95 & 0,91 & 0,91 & 0,93 & 0,96 \\
\hline $20-40$ & 0,92 & 0,94 & 0,93 & 0,93 & 0,94 \\
\hline $0-20$ & 0,38 & 0,41 & 0,48 & 0,37 & 0,40 \\
\hline $0-5$ & 0,99 & 0,98 & 0,99 & 0,99 & 0,99 \\
\hline $5-10$ & 0,95 & 0,97 & 0,96 & 0,97 & 0,94 \\
\hline $10-20$ & 0,89 & 0,94 & 0,91 & 0,94 & 0,96 \\
\hline $20-40$ & 0,95 & 0,96 & 0,96 & 0,97 & 0,92 \\
\hline $0-20$ & 0,95 & 0,99 & 0,97 & 0,98 & 0,95 \\
\hline $0-5$ & 0,76 & 0,82 & 0,89 & 0,77 & 0,59 \\
\hline 5-10 & 0,83 & 0,78 & 0,87 & 0,84 & 0,69 \\
\hline $10-20$ & 0,93 & 0,91 & 0,88 & 0,88 & 0,96 \\
\hline $20-40$ & 0,85 & 0,87 & 0,89 & 0,97 & 0,94 \\
\hline $0-20$ & 0,82 & 0,84 & 0,78 & 0,86 & 0,95 \\
\hline $0-5$ & 0,81 & 0,91 & 0,92 & 0,88 & 0,78 \\
\hline 5-10 & 0,92 & 0,88 & 0,90 & 0,82 & 0,80 \\
\hline $10-20$ & 0,89 & 0,83 & 0,87 & 0,92 & 0,93 \\
\hline $20-40$ & 0,83 & 0,83 & 0,81 & 0,87 & 0,81 \\
\hline $0-20$ & 0,85 & 0,87 & 0,82 & 0,77 & 0,84 \\
\hline $0-5$ & 0,57 & 0,75 & 0,66 & 0,78 & 0,59 \\
\hline 5-10 & 0,78 & 0,69 & 0,64 & 0,87 & 0,84 \\
\hline $10-20$ & 0,35 & 0,71 & 0,72 & 0,75 & 0,74 \\
\hline $20-40$ & 0,21 & 0,44 & 0,36 & 0,48 & 0,41 \\
\hline $0-20$ & 0,59 & 0,73 & 0,78 & 0,62 & 0,72 \\
\hline
\end{tabular}


Tabela 3. Teores médios de K, Ca e Mg em solos sob diversos usos, com seus respectivos desvios padrão da média. É apresentado o teor médio obtido com 5 ferramentas de amostragem. O valor de r corresponde à correlação do teor obtido com a magnitude do desvio padrão.

\begin{tabular}{|c|c|c|c|c|c|c|}
\hline \multirow{3}{*}{ Uso do solo } & \multicolumn{2}{|c|}{ Potássio } & \multicolumn{2}{|c|}{ Cálcio } & \multicolumn{2}{|c|}{ Magnésio } \\
\hline & Teor & Desvio & Teor & Desvio & Teor & Desvio \\
\hline & $\mathrm{mmol} \mathrm{dm}^{-3}$ & $\%$ & $\mathrm{mmol} \mathrm{dm}^{-3}$ & $\%$ & $\mathrm{mmol} \mathrm{dm}^{-3}$ & $\%$ \\
\hline mata & 1,0 & 33 & 7,9 & 16 & 3,3 & 23 \\
\hline eucalipto & 0,4 & 18 & 6,6 & 5 & 2,4 & 4 \\
\hline café & 1,1 & 43 & 12,8 & 25 & 1,8 & 31 \\
\hline cerrado & 0,5 & 54 & 3,2 & 32 & 2,6 & 28 \\
\hline pasto & 0,7 & 50 & 5,5 & 43 & 0,5 & 30 \\
\hline braquiária & 1,5 & 45 & 6,5 & 20 & 2,6 & 36 \\
\hline braquiária & 1,1 & 32 & 7,3 & 16 & 2,4 & 48 \\
\hline braquiária & 0,5 & 51 & 8,3 & 23 & 4,3 & 13 \\
\hline braquiária & 0,9 & 78 & 16,2 & 13 & 10,1 & 16 \\
\hline sem. direta soja & 1,4 & 26 & 27,9 & 64 & 10,7 & 19 \\
\hline sem. direta soja & 1,1 & 17 & 17,5 & 16 & 8,1 & 37 \\
\hline grãos, sem. dir. & 3,0 & 32 & 41,0 & 22 & 16,1 & 22 \\
\hline Milho, conv. & 0,4 & 60 & 15,0 & 30 & 4,6 & 26 \\
\hline Grãos, conv. & 2,4 & 29 & 31,0 & 15 & 14,0 & 12 \\
\hline horta & 4,2 & 9 & 54,9 & 10 & 12,0 & 7 \\
\hline Valor de r & \multicolumn{2}{|c|}{ - 0,53* } & \multicolumn{2}{|c|}{$-0,07^{\mathrm{ns}}$} & \multicolumn{2}{|c|}{$-0,42^{\mathrm{ns}}$} \\
\hline
\end{tabular}

* Valor de r significativo no nível de $5 \%$

ns Valor de r não significativo
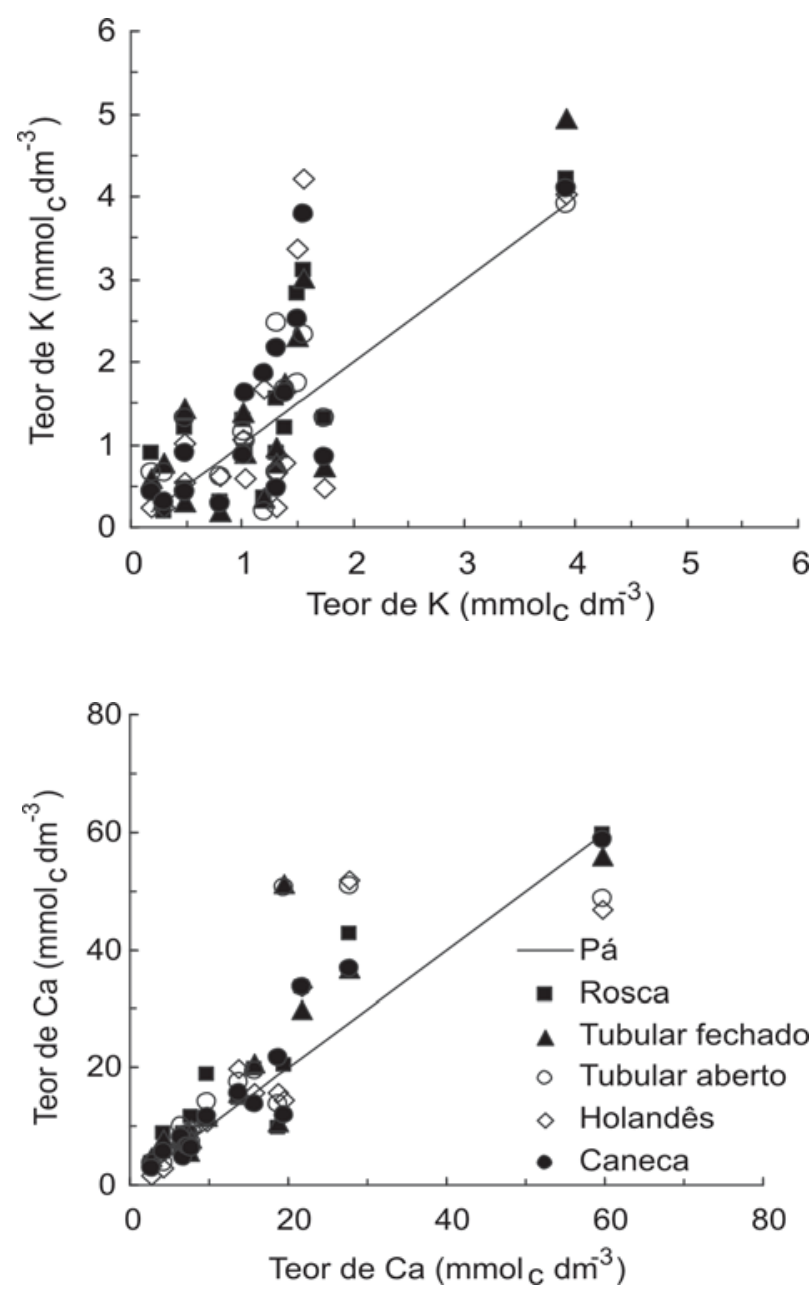

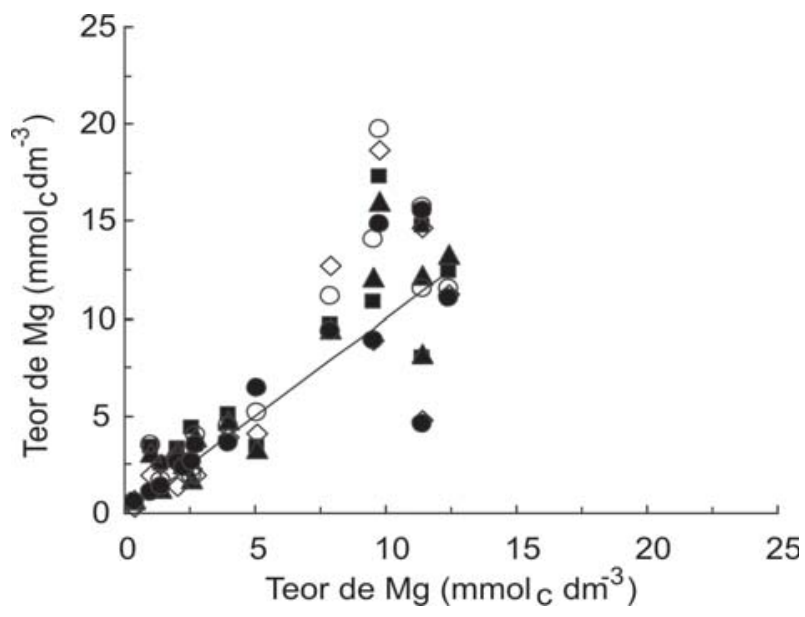

Figura 3: Relações entre os valores obtidos para teores de K, Ca e Mg com seis ferramentas de amostragem. A linha cheia mostra os resultados obtidos com a pá de corte, tomada como referência, correspondente à relação 1:1.

As variações observadas no caso da Matéria Orgânica do Solo (Tabela 2) têm pouca significância, do ponto de vista de análise de terra para fins de fertilidade, pois a matéria orgânica não tem sido utilizada como referência para recomendação de adubação.

Mesmo com o cuidado de se coletar, no presente trabalho, amostras de locais muito próximos, não pode ser descartada completamente a variabilidade local. Há que se considerar ainda uma pequena variabilidade laborato- 
rial. No entanto, como normalmente os resultados obtidos no campo são confrontados com uma tabela de recomendação, haveria a necessidade de considerar a ferramenta utilizada para as amostras empregadas na confecção da tabela de recomendação, o que não é possível. No presente trabalho, a pá de corte foi considerada como padrão, em razão de resultados favoráveis a esta ferramenta que se encontram na literatura. Entretanto, ela provavelmente não foi empregada no desenvolvimento das tabelas de recomendação de adubação e calagem. Assim, de fato, ela não pode ser considerada padrão.

\section{CONCLUSÕES}

O tempo demandado para amostragem com a pá de corte é, em geral, o dobro do que com os trados e, dentre os trados, o mais rápido é o de rosca. Na determinação da matéria orgânica, da acidez do solo (ativa e potencial), do alumínio trocável e do fósforo disponível podem ser utilizadas, indistintamente, todas as ferramentas empregadas. Para as bases trocáveis do solo, as ferramentas empregadas resultaram, na maioria das vezes, em resultados diferentes dos obtidos pela pá de corte.

\section{REFERÊNCIAS}

Alvarez V VH \& Guarçoni MA (2003) Variabilidade horizontal da fertilidade do solo de uma unidade de amostragem em sistema plantio direto. Revista Brasileira de Ciência do Solo, 27:297310 .

Bacchi GS, Sparovek G \& Franco AP (1995) Influência de diferentes métodos de coleta de amostras no resultado de análises de terra. In: XXV Congresso Brasileiro de Ciência do Solo, Viçosa. Anais, Viçosa, p. 589.

EMBRAPA (1997) Manual de métodos de análises de solo. Rio de Janeiro, Serviço Nacional de Pesquisa do Solo. 212p.

EMBRAPA (1999) Sistema brasileiro de classificação de solos. Rio de Janeiro, Centro Nacional de Pesquisa de Solos. 412p.

Mischan MM \& Pinho, SZ (1996) Experimentação agronômica: dados não balanceados. Botucatu, FUNDIBIO. 456 p.

Oliveira FHT de, Arruda JA de, Silva IF da \& Alves JC (2007) Amostragem para avaliação da fertilidade do solo em função do instrumento de coleta das amostras e de tipos de preparo do solo. Revista Brasileira de Ciência do Solo, 31: 973-983.

Raij B Van, Andrade JC, Cantarella H \& Quaggio JA (2001). Análise química para avaliação da fertilidade de solos tropicais. Campinas: Instituto Agronômico. 285p.

Raij B Van, Cantarella H, Quaggio JA \& Furlani AMC (1996) Recomendações de adubação e calagem para o Estado de São Paulo. 2 ed. Campinas: Instituto Agronômico \& Fundação IAC. 285p.

Schlindwein JA \& Anghinoni I (1998) Variabilidade dos índices de fertilidade do solo no sistema plantio direto e coleta de amostras de solo. In: Reunião Sulbrasileira de Ciência do solo, 2, Santa Maria, NRS/SBCS. Resumos expandidos, p. 142-145.

Schlindwein JA \& Anghinoni I (2002) Tamanho da subamostra e representatividade da fertilidade do solo no sistema plantio direto. Ciência Rural, 32:963-968.
Schlindwein JA \& Anghinoni, I (2000) Variabilidade horizontal de atributos de fertilidade e amostragem do solo no sistema plantio direto. Revista Brasileira de Ciência do solo, 24:85-91.

Silva AC \& Machado JFV (1997) Influência de diferentes ferramentas de coleta de amostras de terra, em área de pastagem, nos resultados de análises químicas de rotina. In: XXVI Congresso Brasileiro de Ciência do solo, Rio de Janeiro. Anais, CD-ROOM.

Zar JH (1996) Biostatistical Analysis. 3 ed. Londres: Prentice Hall. 354p. 